\title{
Solving Technological, Pedagogical, and Psychological Problems in Mobile Learning
}

\author{
https://doi.org/10.3991/ijim.v16i02.26205 \\ Fadi Sakka ${ }^{1}$, Alena Gura $^{2(\mathbb{})}$, Valentina Latysheva ${ }^{3}$, \\ Elena Mamlenkova ${ }^{4}$, Olga Kolosova ${ }^{5,6}$ \\ ${ }^{1}$ Department of Business and Quality Management, Hamdan \\ Bin Mohammed Smart University, Dubai, UAE \\ ${ }^{2}$ Department of History, Philosophy and Psychology, Kuban State \\ Technological University, Krasnodar, Russian Federation \\ ${ }^{3}$ Department of Sociology, Psychology and Social Management, Moscow Aviation Institute \\ (National Research University), Moscow, Russian Federation \\ ${ }^{4}$ Department of Nursing Management and Social Work, Sechenov First Moscow State Medical \\ University (Sechenov University), Moscow, Russian Federation \\ ${ }^{5}$ Department of Marketing, State University of Management, Moscow, Russian Federation \\ ${ }^{6}$ Department of Sociology and Advertising Communications, Russian State University \\ named by A.N. Kosygina (Technology. Design. Art), Moscow, Russian Federation \\ gurada@kubstu.ru
}

\begin{abstract}
Aim/Purpose: This paper aims to explore the various problems associated with the technological, pedagogical, and psychological aspects of mobile learning and develop recommendations for its improvement. Background: Mobile learning becomes increasingly popular today. This type of learning is relatively new. It has recently gained popularity due to the pandemic restrictions in 2020 . As mobile learning is being actively used, educators, students, and other professionals begin to note its positive and negative sides. Methodology: The study is based on the method of experiment as well as an online 11-item questionnaire was conducted (developed by authors) with 110 teachers in Russian universities (Russian State University named by A.N. Kosygina, I.M. Sechenov First Moscow State Medical University, and Kuban State Technological University). Contribution: The practical significance and prospects for further research are based on the possibility of using the results in further study of the problem of the impact of mobile applications on specific indicators. Findings: It was found that, given the great prevalence of mobile devices today, there is every reason to implement mobile learning at universities. However, there are infrastructural problems that prevent the widespread use of this mode of delivery (problems with the Internet, old gadgets that do not support 4G, lack of technical support, etc.). Teachers also mention a set of problems associated with the quality of such training, which are mainly related to pedagogical and psychological aspects of the process. About $56 \%$ of university teachers say that students often behave irresponsibly during online classes. They are inattentive, tend to skip lessons, and do not hand in the tasks, which leads to a decline of knowledge and failing at tests and exams. Around $68 \%$ of teachers have difficulties adapting their teaching methods to a mobile learning environment. Recommendations for Practitioners
\end{abstract}


and Researchers: This study proposes structured recommendations to improve the quality of mobile learning by advancing technology skills, adapting mobile learning to the needs of universities, and raising the motivation of teachers and students. Impact on Society: The results of the study can be used to analyze and compare the impact of mobile learning on society, efficiency in various fields, as well as mobile learning of students on future employment and life in society. Future Research: In the future it will be important to conduct a comparative analysis of the impact of mobile learning on students and teachers, to study the effectiveness of such learning in general.

Keywords - mobile learning, online learning, psychological and pedagogical barriers, psychology of mobile education, technology

\section{Introduction}

In today's fast changing world, the development of digital technologies have altered all spheres of human life. This process likewise affected education. One of the trends in modern pedagogy is mobile learning, which offers enormous opportunities to improve the process and efficiency of learning, but at the same time brings many problems that must be solved [1]. These problems can be divided into three groups: technological, pedagogical, and psychological. The significance and relevance of mobile learning is not disputed during a pandemic, when there is a need to use distance learning technologies and use a variety of programs and online platforms to conduct it. Therefore, the study of the impact of mobile learning on the perception of educational material by students is relevant.

Mobile learning is a strategy that provides 21st-century children and students with learning opportunities, such as a wide range of portable electronic devices [2]. These devices are connected through a smart classroom network or the Internet to smart components or interactive learning materials and resources. With the help of electronic devices, students are linked to a collaborative, interactive, and innovative learning environment that is controlled by the teacher (instructor) with the help of a Learning Management System (LMS) or Social Online Learning (SOL) tools [3]. Mobile learning can also be used for complementary learning and self-education.

Today, many educators, students, and their parents hold preconceived notions about mobile learning [4]. Their lack of intention to incorporate it into the classroom is a barrier to the implementation of digital technologies in pedagogy. One possible explanation for why teachers do not integrate their technical knowledge into course design and teaching is their attitude towards using technology. A lot of it depends on the acceptance of technologies [5]. There can be many reasons for the lack of acceptance, such as shortage of time and skills, a rigorous curriculum, poor technical infrastructure in higher education institutions, etc. Some university teachers also mention the low learning effectiveness of mobile learning courses.

The main contribution of the proposed research is to identify the challenges and problems of the implementation of mobile forms of education in university curriculum 
and to propose a specific mobile learning integration framework designed to guide teachers in solving the problems that were identified in the work.

This study goal is to analyze the current situation with mobile learning in Russian universities. The focus is on technological, pedagogical, and psychological aspects of the problem. In addition, the paper provides recommendations for the universities, teachers and students to improve the situation.

\section{$1.1 \quad$ Literature review}

During the pandemic, online learning and distance learning became relevant [6]. There is a need to use modern technologies, including mobile learning and mobile applications [7]. This format of learning affects the learning process in general, and students and teachers in particular. Today, IT technologies are entering virtually every aspect of human life. Digital technology has changed the very notion of what it means to be human [8]. In the analysis of the literature by research and systematic criteria, emphasis is placed on three aspects - technological, pedagogical and psychological, so scientific sources relate to modern technology, pedagogy and psychology, as required by the topic of the article.

Mobile learning refers to using mobile devices such as smartphones, tablets, etc., which help to mediate the education process. In some cases, institutions provide students with such devices, and sometimes they use their own. Mobile devices allow teachers and students to learn anywhere and anytime [9]. The features of mobile learning are the ability to combine learning with daily activities, affordable price, and high quality of education, which can be achieved under certain conditions [10].

Today almost every person in the world has a mobile device. For example, 99\% of students in Oman have a phone or a tablet. Al-Emran and Salloum [11] reported sex-based differences in attitudes towards mobile devices among students: male students used mobile devices more. At the same time factors such as age, education and faculty were not significant.

Learning through mobile devices (1) affects the process and products of learning by interacting with other psychological constructs; (2) provides new opportunities to directly influence the learning process or its outcomes; and (3) provides opportunities to collect previously unavailable data that improve understanding and modeling of the learning process [12].

Bernacki et al. [13] studied how mobile devices and new data channels allowed scholars to look at education and its psychological component in a new way.

Two pedagogical and research directions have emerged:

1) The first one is seamless learning in which students can learn whenever they want using a device as mediator to help them interact with varying input from digital media, peers, instructors, and experts.

2) The second one is context-aware ubiquitous learning in which learners explore realworld phenomena in situ and use mobile devices to support immediate learning [13]. 
Several barriers prevent the adoption of mobile learning. To incorporate mobile learning into the learning process, the following challenges must be understood and addressed: administrative, design, technical, assessment, cultural, and social. Other factors, such as resistance to change, social and cultural influences are also important in mobile learning [14].

Some researchers have obtained interesting results regarding the use of mobile learning in education. One article showed that learning materials and tools are effective when designed in a specific way. For example, mobile apps should meet students' needs, and teachers should continuously support them to achieve positive learning outcomes [15].

Some countries (e.g., Iraq) struggle with paying for the costs of mobile learning (gadgets, Internet). The study found that the quality of e-service on online meeting platforms directly affected perceived value and satisfaction but had no direct effect on willingness to pay. Nevertheless, the perceived value is among the prerequisites of satisfaction [16].

Mobile learning offers several innovative tools to improve the quality of learning. Quantitative data analysis showed that teachers positively evaluated the pedagogical use of interactive spherical video-based virtual reality (ISVVR). In addition, the Chinese researchers found that participants' concerns about adopting the ISVVR had already moved beyond an estimated acceptance level and were mostly concerned with integration issues. It is suggested that further teacher professional development efforts are needed to develop and improve the use of ISVVR in practice [17]. According to many authors, mobile technology can promote innovative teaching, communication and problem-solving skills, and critical thinking skills [18]. An open question for the studying remains the assessment of the challenges and difficulties in the implementation of mobile technologies, both on the part of students and on the part of teachers.

The proposed study is designed to partially close the gap in the time-varying assessment of the problems and challenges associated with the introduction of elements or full-fledged mobile learning from the point of view of the educators.

Overall, mobile learning is taking a leap forward. Nevertheless, there are still technological, pedagogical, and psychological issues associated with mobile learning environments.

\subsection{Problem statement}

Today the popularity of mobile learning grows rapidly. At the same time, the topic raises many questions. Since mobile learning is new and there is little experience of its implementation, both teachers and students are constantly faced with problems of various nature (e.g., technological, pedagogical, and psychological). All of these aspects need to be studied to improve the effectiveness of learning. This study focuses on investigating the technological, pedagogical, and psychological problems of mobile learning in universities and developing recommendations to overcome those. The objectives of this study include examining the quality and effectiveness of mobile learning in Russian universities, collecting and analyzing the teacher opinions, identifying the most common problems, and offering solutions. 


\section{Methodology}

\subsection{Research design and sample}

The study is based on the method of experiment as well as an online questionnaire was conducted. Many researchers, for example, Al-Emran and Salloum [11], choose this approach to study mobile technologies in education. This type of method makes it possible to realize the purpose and objectives of the study, as it allows us to explore the impact of mobile learning on students and teachers, based on which we can explore solutions to technological, pedagogical and psychological problems caused by mobile learning. The questionnaire was distributed among 110 teachers in Russian State University named by A.N. Kosygina, I.M. Sechenov First Moscow State Medical University, and Kuban State Technological University. The participants were 28-53 years old and had work experience ranging from 1 to 25 years. The survey participants were selected within the limits of the described limitations by the method of random sampling.

\subsection{Survey}

The teaching staff was informed about the survey via printed invitations, which were distributed in advance. The questionnaire was prepared using Google Docs. It was sent to participants via email on July 1, 2021. The respondents were instructed to send the filled forms by July 5, 2021. All willing teachers from the selected universities were able to take part in the survey.

The questionnaire had 10 close-ended questions and one open-ended question (11):

1. Do you use mobile devices with Internet access (smartphone, tablet, etc.)? (Yes/No)

2. Do you incorporate mobile learning into your work? (Yes/No)

3. Do you consider yourself skilled enough to use mobile devices for teaching purposes? (Yes/No)

4. Does your university have enough technical support for mobile learning? (Yes/No)

5. Does mobile learning allow you to use your usual pedagogical methods? (Yes/No)

6. Does mobile learning allow you to expand your teaching repertoire (Yes/No)

7. Have you noticed any deterioration in student performance after introducing mobile learning? (Yes/No)

8. Have you noticed any improvement in student performance after using mobile learning? (Yes/No)

9. Does mobile learning provide students with a better environment to learn information? (Yes/No)

10. Do you think students improve intelligence and critical thinking when engaged in mobile learning? (Yes/No)

11. Please share your views on the use of mobile learning approaches at your university. Comment on your answers to the above questions (if applicable).

The construct validity of the proposed questionnaire was verified using the study of Alpha Cronbach, where the arithmetic means of the answers to each of the questions 
were used as data. The answers were coded as: "Yes" $=1$, "No" $=0$. Cronbach's calculated alpha $\mathrm{a}=.709$, which indicates an acceptable level of construct validity of the questionnaire. The reliability of the test results was checked using the test-retest method by repeating the survey with the same participants after 2 months and comparing the results obtained coded in the described way using Pearson's direct correlation. The found correlation reached .077 , which indicates a sufficient minimum reliability of this survey.

\subsection{Data analysis and statistical processing}

Completed questionnaires were analyzed by descriptive statistics method, including with the help of statistical software SPSS 22.0. Descriptive statistics was chosen as the best way to initially collect information about the problem under study from the point of view of the respondents. It allows you to form a factual basis for further structured quantitative research with the isolation of research variables.

\section{$2.4 \quad$ Ethical issues}

Before completing the questionnaire, participants had to read and give their consent to the terms and purpose of the study. They were also informed about the details of the study at the time of the invitation.

\section{$3 \quad$ Results and discussion}

1. Do you use mobile devices with Internet access (smartphone, tablet, etc.)? (Yes/No)

All teachers who participated in the study have mobile devices, which means they can use them for various purposes, including education. This suggests an optimistic outlook on the possibility of introducing mobile learning in universities.

2. Do you incorporate mobile learning into your work? (Yes/No)

Most teachers (81 people) said they have already incorporated mobile learning in their classes, while 29 respondents disagreed. Presumably, one of the factors driving this process was the COVID-19 pandemic, which began in 2020 and stimulated distance learning.

3. Do you consider yourself skilled enough to use mobile devices for teaching purposes? (Yes/No)

Fifty-nine teachers answered 'yes' to this question and 51 said 'no'. It means that $46 \%$ of respondents have some kind of difficulty using mobile learning due to a lack of appropriate skills. This problem could be solved with additional courses and through experience exchange with other teachers. 
4. Does your university have enough technical support for mobile learning? (Yes/No)

Less than half of the respondents $(n=38)$ gave a positive answer. This result shows that universities in the Russian Federation still have insufficient technological support, which can be an obstacle for mobile learning. The obvious solutions to this problem are to provide technical support to general-use classrooms and to hire technical specialists. The officials should consider allocating budgets to support the mobile learning infrastructure of universities.

5. Does mobile learning allow you to use your usual pedagogical methods? (Yes/No)

Thirty-five people agreed that mobile learning allowed them to use their usual teaching methods, while 75 people answered 'no'. The high rate of negative answers suggests that it is quite difficult for respondents to adapt their pedagogical methods to mobile learning. To solve the problem, teachers need to work on adapting their pedagogical methods to the conditions of mobile learning. For example, students can be surveyed using special programs or Google Docs; new material can be explained with screen sharing, etc.

6. Does mobile learning allow you to expand your teaching repertoire? (Yes/No)

Most of the respondents ( 73 people) answered positively, while 37 participants answered 'no'. Despite the challenges educators face when deploying mobile learning, $66 \%$ of teachers think it is a promising innovation and intend to use it. This is a good sign because teacher's intention to use of mobile devices in a classroom is one of the primary drivers for the adoption of mobile learning.

7. Have you noticed any deterioration in student performance after using mobile learning? (Yes/No)

62 people said 'yes' to this question and 48 people answered 'no'. This shows that, at this point, mobile education is less effective compared to the traditional learning. One explanation could be that both teachers and students are unfamiliar with this form of education. A gradual shift to blended learning (traditional + distance learning) and measures aimed at raising student motivation can improve mobile learners' performance.

8. Have you noticed any improvement in student performance after using mobile learning? (Yes/No)

Less than half of the participants $(n=43)$ answered 'yes' to this question, while most of the respondents $(n=67)$ answered 'no'. Despite the results in the previous question, $39 \%$ of teachers still believe that student performance improves with mobile learning. The improved performance suggests that the effectiveness depends not only on the teaching, but also on the personality and psychological characteristics of students, their interest, intention, and motivation. This aspect should also be considered when introducing mobile learning. 
9. Does mobile learning provide a better environment for students to learn information? (Yes/No)

More than half of the teachers $(n=57)$ believe that mobile learning offers a variety of opportunities to improve student retention and comprehension of information. A likely explanation is that visual memory is triggered due to the improved visibility of the content.

10. Do you think students improve intelligence and critical thinking when engaged in mobile learning? (Yes/No)

Sixty-eight teachers think that mobile learning does not improve student's intelligence and critical thinking. Such a result could be explained by a reported decline of knowledge during the period of distance learning in the pandemic. Various factors (pedagogical, technological, psychological, etc.) could be at play here. Both teachers and students should strive to improve their performance, and efforts should focus on increasing the motivation of both parties (the frequency of answers to questions $1-10$ is depicted in Figure 1).

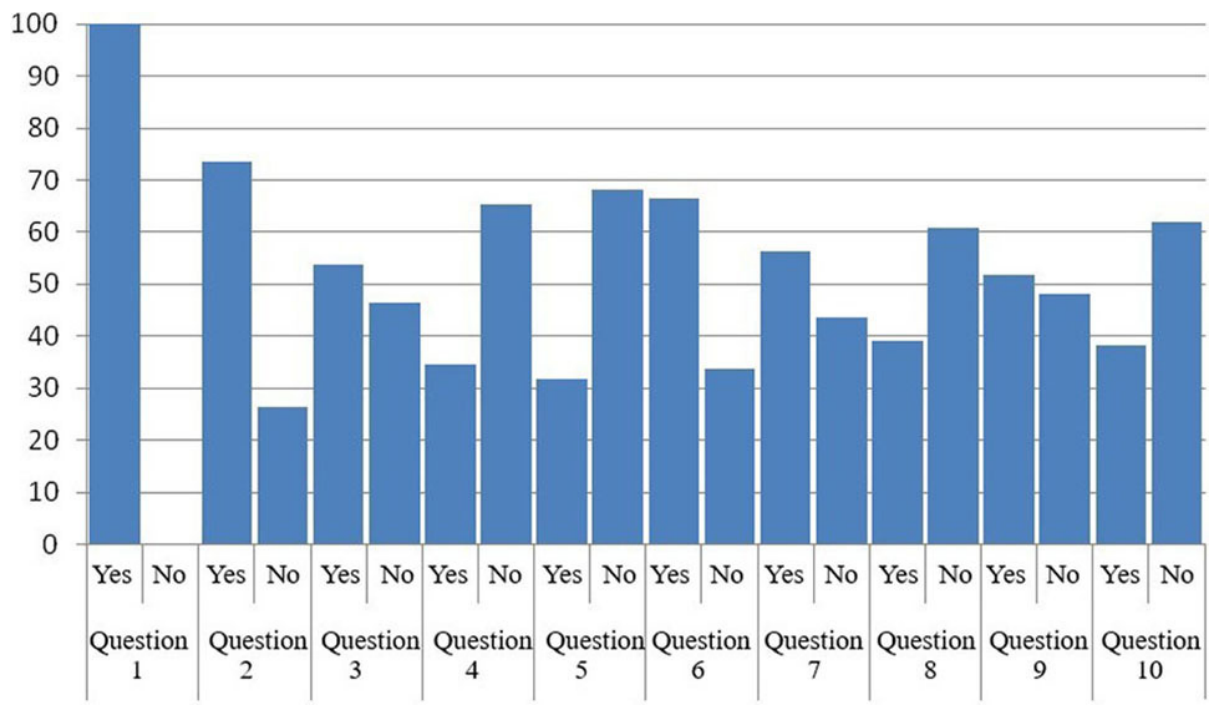

Fig. 1. The teacher survey results, $\%$

11. Please share your views on the use mobile learning approaches at your university. Comment on your answers to the above questions (if applicable).

Teacher Quotes:

Respondent 1: Mobile learning has become most prominent in the second semester of 2020. Because students had to be taught remotely, instructors began to use Zoom, Skype, etc. to conduct classes. In the beginning, there were many problems (e.g., Internet speed, inability to join the session). After a few weeks, the process became more streamlined, but there were still problems. 
Respondent 2: There are difficulties in communicating with students. It is difficult to control how well students learned the material, whether they did homework, what is their current level of knowledge. With full-time education, the process of communication is more effective.

Respondent 3: Not all students take online classes responsibly. Not everyone can work independently. There is a lack of motivation and control. Students say the material is better remembered during a live lecture than when a lecturer is sitting behind the screen.

Respondent 4: Mobile education provides an opportunity to introduce new approaches to learning, but it is not easy. Different factors come into play (technological, psychological). Not suitable for all disciplines. Mobile learning demonstrates good results, for example, in learning foreign languages, but for mathematics, chemistry, etc., it is poorly suited.

Respondent 5: Interpersonal communication is reduced to zero. You have to rely only on the personal responsibility of students.

Responses to question 11 show that the opinion of teachers about mobile learning is mixed, although negative views slightly prevail. Some see the benefits of a blended learning approach, but many teachers do not approve the full transition to mobile learning.

The study was aimed at examining the current state of mobile learning from the technological, pedagogical, and psychological perspectives. The results show an ambiguous attitude to mobile learning in the Russian Federation. Many teachers are not ready to switch to this mode of teaching or experience some difficulties in this regard. The attitude to mobile learning and the level of technophobia varies from country to country. The main problem in developing countries is the lack of infrastructure [19].

Researchers highlight several psychological aspects of the transition to mobile learning. Teachers, first of all, need to improve their IT skills. Students usually lack a responsible attitude and the ability to work independently. Trends in the acceptance of mobile learning by teachers are as follows:

1) more experienced teachers tend to struggle more with the adoption of mobile learning;

2) less experienced teachers tend to be familiar with this technology and willingly accept it;

3) teachers who prefer mobile learning are familiar with this technology and engage in active professional development (including online);

4) teachers who are aware of the importance of external influences tend to be more positive about online learning and prefer to go digital [9].

The psychological characteristics of the students also influence learning effectiveness (see Figure 2). Students with a strong intention to try new technologies (higher personal innovativeness) and those who actively engage in learning and rely on information from others for problem-solving (accommodating learning style) are more likely to use mobile learning in informal contexts. In contrast, those learners who rely on one's own analysis and reflection (assimilative learning style) are more likely to use formal platforms for mobile learning [20]. 


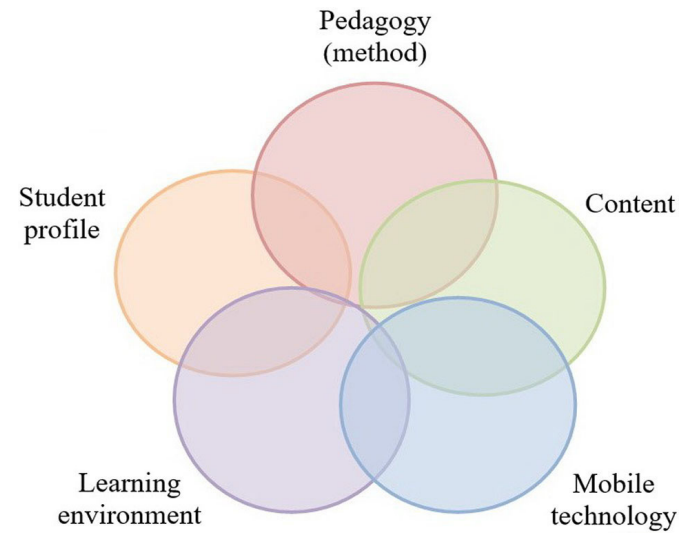

Fig. 2. A 5-axis mobile learning integration framework

Source: Developed by the authors based on data from Zidoun et al. [18]

For many students, mobile learning is an effective alternative to traditional learning. Some authors report positive effects of mobile learning. For example, using mobile technology in medical education results in students (1) enhancing their clinical competence and confidence, (2) gaining and deepening theoretical knowledge, and forming (3) positive attitudes to and perceptions about mobile learning [21].

\subsection{Case studies}

In contrast to teachers, students often feel positive about mobile learning. Researchers in Malaysia were given good feedback from students who participated in mobile learning. Students were happy to use it and felt supported and motivated while using the mobile learning app [22].

According to researchers from South Africa, most students used their tablets for lecture notes (women tended to do so more than men did). Some problems with mobile learning were poor on- and off-campus Wi-Fi connections; some students did not like the idea of using mobile devices and preferred traditional learning methods [23].

In mobile learning, it is important to choose the right teaching method. Teachers' experience shows that case technology is a preferred method in mobile learning. Project-oriented learning shows poorer results. Agila-Palacios et al. [24] analyzed 'two active methods for the development of digital competencies using mobile devices. The first method was project-oriented learning (POL), while the second was casebased learning $(\mathrm{CBL})$. The results showed that students who were taught according to POL improved their competencies by $7 \%$. Those students who were engaged in CBL improved all four competencies, such as interaction ( $+8 \%)$, information sharing $(+6 \%)$, collaboration $(+4 \%)$, and netiquette $(+4 \%)$.

Language learning with mobile technology has become very popular in Turkey and in most developing countries. Mobile-Assisted Language Learning (MALL) is derived from Computer-Assisted Language Learning (CALL) and mobile learning. Both types of learning focus on contextual learning, flexibility, and active participation in 
the community activities. MALL uses key mobile technologies for language learning, such as pocket electronic dictionaries, handheld personal computers, cell phones, MP3 players, and tablets [25]. Compared to all the analyzed studies, common to ours is the fact of the impact of mobile learning on the effectiveness of the educational process and indicators of motivation and academic success of students.

Mobile learning promotes better recall of information. Researchers in the United States have found that repetitive retrieval (extraction) of information is superior to mechanical methods of learning. Retrieval and repeated retrieval practices are thought to reinforce retrieval pathways so that data can be more easily retrieved later [26].

In a study by Sattarov et al. [27], many participants said that mobile learning should be combined with traditional methods because it offers many features that cannot be implemented in a conventional classroom setting. According to Uzbek researchers, using mobile technology to support the traditional learning process (both in the classroom and during homework) to improve the quality of learning has the following advantages:

- having an additional channel of student-teacher interaction;

- the ability to present a wider range of educational material and improve visibility;

- the possibility of using a game form of learning;

- increased visibility and interactivity;

- the possibility of organizing repetition of the training material;

- the opportunity to organize students' independent work using mobile devices.

According to scientists from Ecuador and Spain, the use of mobile technology puts a student at the center of the learning process. This makes the teacher a mediator between content and knowledge [28].

Mobile learning has been introduced into classrooms just recently, and people have different attitudes towards it. Engaging students to learn in this way and participate in the educational process leads to the acceptance of mobile learning in general [29].

Some authors offer a series of recommendations for implementing and improving the quality of mobile education. The advice aims to help (1) switch from using mobile devices as data sources to mobile-assisted collaborative learning, (2) design a comprehensive training program for teachers to incorporate mobile learning into the classroom; and (3) adapt mobile learning practices to the challenges of distraction and multitasking [30].

This article offers a new, structured perspective on the challenges of mobile learning from a comparative perspective of problem assessment by teachers and students. The proposed perspective, as shown by comparison of sources with similar studies, is close for many developing countries and the Russian Federation, and the recommendations are of practical importance for a wider international context.

Based the information given above and the results of this study, the following recommendations can be proposed:

- Universities should improve the technological equipment of educational institutions, motivate teachers to use mobile learning (extra pay, time, activities), incorporate mobile learning into curricula; motivate students (contests, awards, points). 
- Teachers should improve skills in using mobile learning methods, allocate time for self-study and professional development, share experiences with other teachers, and adapt teaching methods to mobile learning environments.

- Students should improve time-management skills, take a responsible and conscious approach to mobile learning, avoid distractions during online classes, learn to work independently, and use a variety of online tools and information, not just those provided by the university.

\section{Conclusions}

\subsection{Theoretical implication}

This study was aimed at exploring the opportunities, problems, and prospects for the adoption of technological, pedagogical, and psychological techniques in mobile learning. The study contributes to identification of the challenges and problems of the implementation of mobile forms of education in university.

\subsection{Practical implications}

The results showed that $100 \%$ of the respondents (university teachers) use mobile devices with Internet access in their daily activities. Therefore, it is a matter of short time before they start using them in class. In fact, $74 \%$ of the teachers said they already have experience in using mobile technology in teaching. A high percentage of teachers familiar with mobile learning is probably connected to the COVID-19 pandemic, which has forced many educational institutions to switch to distance learning. Another reason may be that the education market provides a broad range of platforms and tools to ease traditional teaching.

The teachers had mixed opinions regarding the effectiveness of mobile learning. Many (56\%) believe that mobile learning has improved students' knowledge, but there are also those (39\%) who reported deterioration. The poor performance of some students can be contributed to psychological aspect of mobile learning (poor time-management skills, lack of focus, low motivation, irresponsibility, and inattention). Many teachers $(75 \%)$ also reported difficulties in adapting their teaching methods to a mobile learning environment. The main obstacle is the lack of direct communication between teachers and students. However, teachers noted that giving students the opportunity to communicate with each other could improve their academic performance. That opportunity can be provided by deploying distance learning programs and platforms.

\subsection{Contribution and future direction}

From a technological point of view, the current situation is that almost all participants in the education process have mobile devices at their disposal, but the universities do not have the infrastructure to fully exploit all the technological possibilities and tools that exist today. This paper sheds light on distinct (i.e., technological, pedagogical, 
and psychological) challenges associated with the adoption of mobile learning. It will be of interest to university administrators, teachers, students, parents, and everyone interested in modern pedagogy and psychology. The practical significance and prospects for further research are based on the possibility of using the results in further study of the problem of the impact of mobile applications on specific indicators. In the future it will be important to conduct a comparative analysis of the impact of mobile learning on students and teachers, to study the effectiveness of such learning in general. Future research may focus on developing mobile teaching methods to overcome identified challenges and improve the effectiveness of mobile education.

\subsection{Research limitations}

The results of the study can be considered reliable. However, it should be considered that it took place just in two universities in the Russian Federation and the number of participants was limited. The limitations of the study are based on a small sample and a small number of universities taken to conduct the experiment, which limits the results and makes it impossible to monitor the situation regarding mobile learning in all universities in the country. To address the limitations, the experience of other countries with the ability to address technological, pedagogical and psychological issues related to mobile learning should be taken into account.

\section{Acknowledgment}

Not applicable.

\section{References}

[1] Naciri, A., Baba, M., Achbani, A., Kharbach, A. (2020). Mobile Learning in higher education: Unavoidable alternative during COVID-19. AQUADEMIA, 4(1): ep20016. https://doi.org/10.29333/aquademia/8227

[2] Papadakis, S. (2020). Robots and robotics kits for early childhood and first school age. International Journal of Interactive Mobile Technologies, 14(18): 34-56. https://doi.org/ 10.3991/ijim.v14i18.16631

[3] Al-Hunaiyyan, A., Al-Sharhan, S., Alhajri, R. (2017). A new mobile learning model in the context of smart classroom environment: A holistic approach. International Journal of Interactive Mobile Technologies, 11(3): 39-56. https://doi.org/10.3991/ijim.v11i3.6186

[4] Larsson, K. (2017). Understanding and teaching critical thinking - A new approach. International Journal of Educational Research, 84: 32-42. https://doi.org/10.1016/j.ijer.2017.05.004

[5] Rienties, B., Giesbers, B., Lygo-Baker, S., Ma, H., Rees, R. (2014). Why some teachers easily learn to use a new virtual learning environment: a technology acceptance perspective. Interactive Learning Environments, 24(3): 539-552. https://doi.org/10.1080/10494820.201 $\underline{4.881394}$

[6] Karakose, T., Yirci, R., Papadakis, S. (2021). Exploring the interrelationship between COVID-19 phobia, work-family conflict, family-work conflict, and life satisfaction among school administrators for advancing sustainable management. Sustainability, 13(15): 8654. https://doi.org/10.3390/su13158654 
[7] Karakose, T., Yirci, R., Papadakis, S., Ozdemir, T.Y., Demirkol, M., Polat, H. (2021). Science mapping of the global knowledge base on management, leadership, and administration related to COVID-19 for promoting the sustainability of scientific research. Sustainability, 13: 9631. https://doi.org/10.3390/su13179631

[8] Borba, M., Askar, P., Engelbrecht, J., Gadanidis, G., Llinares, S., Aguilar, M. (2016). Blended learning, e-learning and mobile learning in mathematics education. ZDM Mathematics Education, 48(5): 589-610. https://doi.org/10.1007/s11858-016-0798-4

[9] Christensen, R., Knezek, G. (2018). Readiness for integrating mobile learning in the classroom: Challenges, preferences and possibilities. Computers in Human Behavior, 78: 379-388. https://doi.org/10.1016/j.chb.2017.07.046

[10] Kumar, S. (2020). Impact of e-Learning technologies in higher education. Journal of Ideal Review, 21(2): 12-18.

[11] Al-Emran, M., Salloum, S. (2017). Students' attitudes towards the use of mobile technologies in e-evaluation. International Journal of Interactive Mobile Technologies, 11(5): 195-202. https://doi.org/10.3991/ijim.v11i5.6879

[12] Bernacki, M., Greene, J., Crompton, H. (2020). Mobile technology, learning, and achievement: Advances in understanding and measuring the role of mobile technology in education. Contemporary Educational Psychology, 60: 101827. https://doi.org/10.1016/j. cedpsych.2019.101827

[13] Bernacki, M., Crompton, H., Greene, J. (2020). Towards convergence of mobile and psychological theories of learning. Contemporary Educational Psychology, 60101828. shttps://doi.org/10.1016/j.cedpsych.2019.101828

[14] Al-Hunaiyyan, A., Alhajri, R., Al-Sharhan, S. (2018). Perceptions and challenges of mobile learning inKuwai. Journal of King Saud University - Computer and Information Sciences, 30: 279-289. https://doi.org/10.1016/j.jksuci.2016.12.001

[15] Klimova, B. (2019). Impact of mobile learning on students' achievement results. Education Sciences, 9(2): 90. https://doi.org/10.3390/educsci9020090

[16] Demir, A., Maroof, L., Khan, N., Ali, B. (2020). The role of E-service quality in shaping online meeting platforms: a case study from higher education sector. Journal of Applied Research in Higher Education, in press. https://doi.org/10.1108/JARHE-08-2020-0253

[17] Geng, J., Chai, C., Jong, M., Luk, E. (2019). Understanding the pedagogical potential of Interactive Spherical Video-based Virtual Reality from the teachers' perspective through the ACE framework. Interactive Learning Environments, 29(4): 618-633. https://doi.org/10.10 80/10494820.2019.1593200

[18] Zidoun, Y., Dehbi, R., Talea, M., Arroum, F. (2019). Designing a theoretical integration framework for mobile learning. International Journal of Interactive Mobile Technologies, 13(12): 152-170. https://doi.org/10.3991/ijim.v13i12.10841

[19] Bukht, R., Heeks, R. (2018). Digital economy policy in developing countries. DIODE Working Papers; No. 6. https://doi.org/10.2139/ssrn.3540027

[20] Karimi, S. (2016). Do learners' characteristics matter? An exploration of mobile-learning adoption in selfdirected learning. Computers in Human Behavior, 63: 769-776. https://doi. org/10.1016/j.chb.2016.06.014

[21] Koohestani, H., Arabshahi, S., Fata, L. (2018). The educational effects of mobile learning on students of medical sciences: A systematic review in experimental studies. Journal of Advances in Medical Education \& Professionalism, 6(2): 58-69.

[22] Moorthy, K., Yee, T.T., T'ing, L.C., Kumaran, V.V. (2019). Habit and hedonic motivation are the strongest influences in mobile learning behaviours among higher education students in Malaysia. Australasian Journal of Educational Technology, 35(4): 174-191. https://doi. org/10.14742/ajet.4432 
[23] Lazarus, L., Sookrajh, R., Satyapal, K. (2017). Tablet technology in medical education in South Africa: a mixed methods study. BMJ Open, 7: e013871. https://doi.org/10.1136/ bmjopen-2016-013871

[24] Agila-Palacios, M., Garcia-Valcarcel, A., Ramírez-Montoya, M. (2021). Influence of active methodologies: Projects and cases in the development of digital competences with mobile devices. Journal of Applied Research in Higher Education, in press. https://doi.org/10.1108/ JARHE-05-2020-0149

[25] Çakmak, F. (2019). Mobile Learning and mobile assisted language learning in focus. Language and Technology, 1(1): 30-47.

[26] Huffman, W., Hahn, S. (2015). Cognitive principles in mobile learning applications. Psychology, 6(4): 456-463. https://doi.org/10.4236/psych.2015.64043

[27] Sattarov, A., Yusupov, R., Khaitov, F., Jomurodov, D., Ahmedov, F., Khonimkulov, U. (2020). Some didactic opportunities of application of mobile technologies for improvement in the educational process. Journal of Critical Reviews, 7(11): 348-352.

[28] Criollo-C, S., Guerrero-Arias, A., Jaramillo-Alcázar, Á., Luján-Mora, S. (2021). Mobile learning technologies for education: Benefits and pending issues. Applied Sciences, 11(9): 4111. https://doi.org/10.3390/app11094111

[29] Ismail, N.S., Harun, J., Zakaria, M.A.Z.M., Salleh, S.M. (2018). The effect of Mobile problem-based learning application DicScience PBL on students' critical thinking. Thinking Skills and Creativity, 28: 177-195. https://doi.org/10.1016/j.tsc.2018.04.002

[30] Pedro, L., Barbosa, C., Santos, C. (2018). A critical review of mobile learning integration in formal educational contexts. International Journal of Educational Technology in Higher Education, 15: 10. https://doi.org/10.1186/s41239-018-0091-4

\section{$7 \quad$ Authors}

Fadi Sakka is a PhD, Assistant Professor of the Department of Business and Quality Management, Hamdan Bin Mohammed Smart University, Dubai, UAE. Email: F.alsakka@hbmsu.ac.ae

Alena Gura is a PhD of Philosophical Sciences, Associate Professor of the Department of History, Philosophy and Psychology, Kuban State Technological University, Krasnodar, Russian Federation. Email: gurada@,kubstu.ru

Valentina Latysheva is a PhD of Philosophical Sciences, Head of the Department of Sociology, Psychology and Social Management, Moscow Aviation Institute (National Research University), Moscow, Russian Federation. Email: latyshevaVV@mai.ru

Elena Mamlenkova is an Assistant of the Department of Nursing Management and Social Work, I.M. Sechenov First Moscow State Medical University, Moscow, Russian Federation. Email: mamlenkova e a@staff.sechenov.ru

Olga Kolosova is a PhD in Psychological Sciences, Associate Professor of the Department of Marketing, State University of Management, Moscow, Russian Federation; Department of Sociology and Advertising Communications, Russian State University named by A.N. Kosygina (Technology. Design. Art), Moscow, Russian Federation. Email: oa_kolosova@guu.ru

Article submitted 2021-08-12. Resubmitted 2021-10-02. Final acceptance 2021-10-04. Final version published as submitted by the authors. 